artigo

[ PATRÍCIA DE MIRANDA IORIO ]

Doutora em Ciência da Literatura pela Universidade Federal do Rio de Janeiro (UFRJ), mestre em Jornalismo pela Southern Illinois University/SIU-C e graduada em Jornalismo pela PUC-Rio. É docente do curso de Jornalismo da UERJ e do Ibmec-RJ, pesquisadora de ficção seriada e coautora de dois livros sobre a história do futebol no Rio de Janeiro - Paissandu Atlético Clube: pioneiro do esporte no Rio de Janeiro e Rio Cricket e Associação Atlética: mais de cem anos de paixão pelo esporte.

E-mail: patriciaiorio@globo.com

\title{
O uniforme esportivo e sua recriação televisiva
}

\author{
Sports uniform and its recreations on TV
}

[resumo] Ao comparar fotos documentais dos primeiros jogos de futebol realizados no Estado do Rio de Janeiro com produções televisivas - uma jornalística e outra ficcional - destinadas a revisitar esse periodo histórico, este trabalho toma como objeto de análise o uniforme esportivo para discutir a recriação televisiva. Com base nos conceitos de "bios virtual" e "telerrealidade", do teórico da Comunicação Muniz Sodré, a investigação recai sobre a reportagem comemorativa dos 110 anos da primeira partida oficial de futebol no Rio, produzida pelo programa Globo Esporte, e sobre a ficção seriada Lado a lado, ambos exibidos na TV Globo. Globo Esporte; Lado a lado.

[abstract] By comparing documentary pictures of the first soccer games played in the state of Rio de Janeiro with TV productions - a journalistic and a fictional one - aimed to revisit this historical period, this work takes as object of analysis the sportive uniform as a way to discuss TV recreations. Based on the concepts of "virtual bios" and "telereality", developed by Communication theorist Muniz Sodré, this investigation takes in consideration the commemorative report on the $110^{\text {th }}$ anniversary of the first official soccer game at Rio, produced by Globo Esporte show, and the fiction series Lado a lado, both broadcasted by Globo network.

[key words] soccer uniform; history; telereality; Globo Es- 
Tecido inteligente, corte a laser, fibras tecnológicas, costura a base de cola. Cada vez mais os uniformes esportivos são desenvolvidos para promover conforto térmico, mobilidade, leveza, bem-estar. 0 vestuário high tech "gerencia" a transpiração e a refrigeração, absorve rapidamente o suor e a umidade, elimina odores, hidrata o corpo durante o esforço físico e permite maleabilidade e secagem veloz do tecido, sempre de acordo com "as necessidades fisiológicas, ergonômicas e antropométricas do atleta" (SANCHES et alli, 2010, p. 23). Tudo para garantir melhor desempenho.

A preocupação com o desempenho, no entanto, nem sempre se ocupou do vestuário de jogadores. Muito pelo contrário: houve um tempo em que o uniforme era 0 que menos importava!

Quando o futebol desembarcou no Rio de Janeiro, a bordo dos sonhos de jovens estrangeiros e descendentes de estrangeiros que haviam experimentado o esporte na Inglaterra ou na Suiça, o exercício físico, a prática ao ar livre, a camaradagem e 0 espírito lúdico do jogo eram o grande atrativo. Naquela época, a ideia de uniforme como uma peça de vestuário adequada à prática do esporte ainda não se colocava: bastava que diferenciasse um time de seu adversário. Em 1971, aos 85 anos, Edwin H. Cox, então o último jogador contemporâneo dos primeiros jogos de futebol na cidade, relembrou o passado e, diante de tudo que já tinha visto do esporte até aquela data, foi categórico: o futebol começou "sem uniformes" (CAVALCANTI; MASSON, 1971, p. 36).

Recentemente, quando o programa Globo Esporte e a novela Lado a lado, ambos exibidos na TV Globo, dedicaram-se a revisitar os primeiros jogos de futebol no país, a grande preocupação da produção era o uniforme. Mais do que a precisão dos dados históricos ou mesmo a forma de jogar da época, ocuparam-se primeiramente da visualidade do esporte: 0 uniforme era a estrela principal!

Como em toda produção televisiva, o importante era "dar vídeo", comunicar visualmente. A partir de informações fornecidas por uma consultoria, ${ }^{1}$ uniformes foram confeccionados e equipamentos esportivos de época foram localizados ou recriados. $\mathrm{Na}$ tela, a fidelidade algumas vezes cedeu lugar à comunicabilidade na tarefa de contar uma história. Afinal, era apenas uma "representação". Uma "representação" televisiva.

Registros fotográficos do uniforme usado por jogadores e árbitros nos primeiros jogos de futebol realizados no Rio de Janeiro são imagens documentais de um passado histórico num país que hoje se concebe como a "pátria de chuteiras". Ao visitar a origem do esporte que se tornou a paixão nacional, o telejornal e a ficção televisiva estabelecem nova referência na memória coletiva sobre o futebol. Que referência seria essa? Seria uma representação que aponta para a realidade ou uma reconstrução mediatizada autoconstituída?

\section{0 uniforme dos primeiros jogos}

Oficialmente, o primeiro registro da introdução do futebol enquanto esporte (e não recreação) em terras fluminenses se deu pelas mãos do descendente de estrangeiros Oscar Cox, em 1898, quando trouxe da Suiça, onde estudava, duas bolas de couro. Jovem residente no Rio de Janeiro, Cox tinha em mente reunir seus companheiros de cricket, o grande esporte da época entre os estrangeiros e os anglo-brasileiros que ali moravam, para divulgar o futebol.

A população da cidade, entre curiosa e surpresa, estranhava a prática de exercícios físicos (eram tidos como "coisa de escravo"), o porte encorpado dos jogadores (que, apesar de pertencerem à elite ou à burguesia abastada carioca, não cultivavam a estética franzina vigente) e o fato de esportes como o cricket e o tênis de grama serem realizados ao ar livre - as ruas fétidas e os terrenos abandonados apenas abrigavam mendigos e lixo, fora que a exposição ao sol tornava demasiadamente morenas as peles alvas da elite, que seguia os padrões estéticos europeus.

Foi nesse contexto que Cox tentou seduzir cricketers a usar os pés e não mais as mãos para controlar a bola. Começou com os sócios dos clubes que seu pai fundara, o Rio Cricket Club, então temporariamente chamado de Clube Brasileiro de Cricket e depois Paysandy Cricket Club (hoje Paissandu Atlético Clube), na época situado no bairro carioca de Laranjeiras, e o Rio Cricket and Athletic Association (hoje Rio Cricket e Associação Atlética), em Niterói. Treinou passes, dribles e chutes a gol. Já contando com jogadores emprestados do cricket, pareceu natural que o traje de jogo fosse também emprestado do esporte mais popular entre os estrangeiros das duas cidades. 
A despeito do sol escaldante e da umidade, e a despeito da amplitude de movimentos exigida pelo cricket, o uniforme dos jogadores respeitava os códigos da elegância da época e a cerimônia de expor em público o corpo que se constituía cada vez mais musculoso e atlético, destoando da cultura local.

0 improviso inspirou o primeiro uniforme do futebol carioca. Assim, quando os estrangeiros do Rio e de Niterói se enfrentaram pela primeira vez, em agosto de 1901, para uma partida de futebol no campo de cricket reconfigurado para as medidas do novo esporte, os jogadores trajavam vestimentas inusitadas aos olhos de hoje. Vestiam uma adaptação do uniforme do cricket: camisas sociais brancas, de botão e mangas compridas dobradas; calças sociais brancas ou pretas cortadas à altura do joelho; cinto preto; meias longas pretas; sapato de couro claro abotinado, com sola de borracha; e touca em forma de solidéu. Esse último adereço destinava-se a proteger os jogadores do impacto da bola quando cabeceada, já que o equipamento tinha uma amarração grosseira sobre a abertura longitudinal que dava passagem para a câmara de ar.

0 preto e o branco eram combinados de forma a distinguir uma equipe da outra: calça e camisa brancas de um lado, calça preta e camisa branca, de outro. Apenas o árbitro e os árbitros de linha se destacavam: traziam sobre a camisa branca um elegante blazer preto com um brasão na lapela. Às vezes, trocavam a calça branca por

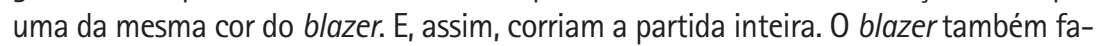
zia parte do uniforme dos jogadores, mas só entravam em campo para a apresentação do time. Em seguida eram descartados.

Confeccionado em tecido plano 100\% algodão e tendo mangas compridas, botões, cinto, "bermudas" na altura do joelho e touca de flanela, o uniforme original do futebol nada tinha de confortável: não era maleável nem deixava pernas e braços livres, de modo a ajustar-se ao movimento do atleta; não era fresco, para aplacar o calor dos trópicos (sobretudo considerando-se que os jogadores eram, em sua maioria, europeus); não era leve (botinas e cinto de couro deixavam seu peso na indumentária); e não assentava (a camisa soltava-se de dentro da calça, as mangas desenrolavam e 0 solidéu se movimentava na cabeça, introduzindo sensação de insegurança).

É bem verdade que o jogo apresentava menos contato físico e era conduzido com menos movimentação em campo. Também é verdade que, nesse início do futebol no Rio, quase não havia espectadores - o que diminuía a preocupação com a identificação dos times pelo uniforme. Diante de uma plateia de quinze pessoas, como a que estava presente no primeiro jogo de futebol no Estado, bastava que os próprios jogadores soubessem quem eram seus adversários.

Com a fundação de novos clubes de futebol e da Liga Metropolitana de Football, em 1905, a preocupação com a identificação dos times já se fazia necessária. E era apenas para isso que os uniformes serviam: indicar quais times estavam em campo. E mesmo assim, tal identificação não era de todo rígida. Tanto que, no fim daquele ano, estando em Londres a passeio e tendo recebido uma carta da diretoria do Fluminense solicitando-lhe a compra de uma dúzia de camisas de lã cinza e branco, as cores do time, Oscar Cox, por uma casualidade, acabou determinando uma súbita e total modificação na identificação da equipe e, segundo Cavalcanti e Masson (1971), não tendo encontrado a padronagem solicitada, trouxe na bagagem camisas de cores vermelho-escuro (grená), verde-garrafa e branco em listras verticais!

Assim como os equipamentos esportivos, os uniformes também eram importados da Europa, acentuando ainda mais a impropriedade do material em relação ao clima carioca. Os blazers de apresentação chegavam em tecido listrado e colorido, e, passada a fase de introdução do esporte, também as camisas foram ganhando cores e listras. A partir de 1911, as encomendas de uniformes vindas do exterior traziam para as camisas a flexibilidade e a porosidade da malha 100\% algodão, um conforto que as camisas sociais não proporcionavam. As bermudas ganharam cadarços para o ajuste na cintura, permitindo o abandono do desconfortável cinto. 
Em foto de 1912 do time campeão da Liga Metropolitana, o Paysandu posa com camisas de malha em manga comprida, tendo cada metade da frente uma cor diferente e amarração com cadarço no decote (IORIO; IORIO, 2001). Na imagem, apenas 0 goleiro veste camisa social e cinto.

Na página do site "Sou Mais Flu", 2 destinada a apresentar o desenho de todos os uniformes utilizados pelo Fluminense ${ }^{3}$ ao longo da história, vê-se aquele estreado em 1903: bermuda e camisa social em tecido plano 100\% algodão; a parte de baixo branca e a parte de cima com uma metade cinza e outra branca, cada manga trazendo uma das cores na frente e outra no verso alternadamente. Vê-se também a camisa tricolor trazida por Cox, que se tornaria a marca do time, usada com bermudas brancas. E ainda, a que registra a adoção da malha em 1911, em padronagem listrada verde-garrafa, grená e branca, com a novidade da gola branca, substituindo definitivamente a camisa social pelo estilo "camisa polo". Só a partir de 1933, com o advento do profissionalismo, o uniforme tricolor passou a adotar mangas curtas e decote em "V".

\section{Revivendo o início do futebol na TV}

Para comemorar os 110 anos da primeira partida oficial de futebol realizada em solo fluminense, o programa de jornalismo esportivo da TV Globo Globo Esporte exibiu no dia 19 de agosto de 2011 uma reportagem especial em que "reviveu" aquele jogo histórico no mesmo campo de outrora, o gramado do Rio Cricket e Associação Atlética, em Niterói. ${ }^{4}$ Sócios do clube foram recrutados para simular a partida. Na bagagem da produção, bola, chuteira e uniformes que reproduziam os originais, segundo consultoria técnica: camisas sociais brancas adquiridas em loja masculina de renome, bermudas brancas e pretas, meias pretas, cintos pretos. Havia apenas um sapato abotinado que seria destacado pela câmera; os demais eram chuteiras pretas comuns. A touca produzida para a cena ganhou uma aba, quase como um boné. Sobre a camisa de botões do árbitro, um blazer preto.

As imagens e as entrevistas traziam as impressões do século XXI sobre o início do século XX no futebol: o calor das camisas e do blazer, a pouca mobilidade das calças cortadas à altura do joelho, o peso, a pouca aderência e o desconforto do sapato esportivo. 0 tratamento imagético dava conta de "envelhecer" as imagens, não só retirando-Ihes muitas vezes a cor, como também fazendo oscilar e "riscando" as cenas na vertical como que a simular as antigas projeções e o desgaste da suposta película fílmica ao longo do tempo decorrido durante os 110 anos que separavam o espectador do momento histórico.

Mais recentemente, a mesma TV Globo voltou a trazer à tona os momentos iniciais do futebol fluminense, dessa vez em linguagem ficcional, quando da exibição da novela Lado a lado, de autoria de João Ximenes Braga e Cláudia Lage. Entre setembro de 2012 e março de 2013, a ficção seriada abordou, entre outros temas, a introdução do esporte no país. Na trama, um grupo de amigos da elite carioca, empolgado com a novidade que fazia sucesso na Europa, se dispõe a trazer o futebol para o Rio, importar uniforme, equipamento e regras, aprender os fundamentos do esporte e difundi-lo entre a burguesia abastada local.

Os "janotas", como eram identificados os burgueses na novela, estavam jogando cricket no clube, quando chega do porto um caixote com a encomenda. ${ }^{5}$ De lá saíram camisas, bermudas, blazers listrados, "chuteiras", meias, toucas e - 0 item mais festejado - a bola! Nas cenas em que aparecem aprendendo e treinando o novo esporte, os atores vestem camisa social, bermuda e meias brancas, além de cinto preto. Nesse momento, a história se passa em 1902 e Fernando (personagem de Caio Blat), tendo visto os ingleses e descendentes de estrangeiros jogar, destacando o nome de Oscar Cox, anima-se com o esporte por ser "de elite". No jogo dos "ingleses", um time veste bermuda (ajustada por corda) e meias brancas, chuteiras pretas e camisa social listrada de vermelho, verde e branco. 0 outro time está de bermudas e meias pretas com camisa social branca ${ }^{6}$.

Nas demais cenas que envolvem o futebol, quer em 1902, quando do início da novela, quer em 1910, quando a trama dá um salto temporal, o uniforme varia pouco. A camisa de tecido branco ganha detalhes em preto no abotoamento ou tem metade da frente e das costas em cinza. ${ }^{7}$ As mangas são sempre compridas, quase nunca usadas arregaçadas. No capítulo do dia 23 de outubro de 2012, ambos os times são 
mostrados entrando em campo, ainda de blazer, suscitando comentários da plateia sobre a elegância natural de um esporte praticado pela elite ${ }^{8}$.

Mais tarde, quando a trama salta para 1910, aparece o primeiro uniforme com camisa de malha: listrado em verde e branco, com gola polo verde e amarração com cadarço no decote em "V".

\section{Entre o fato e a construção televisual}

Quer no telejornal esportivo, quer na telenovela, a história contada é ambientada, antes de tudo, no universo da televisão. É no campo de futebol enquadrado pela câmera de TV que a bola é disputada por jovens do século XXI travestidos de atletas do início do século XX. É pela imagem do televisor de hoje que o público visita o passado. A própria reportagem do Globo Esporte lembra que, na época do jogo inaugural, "não havia tevê em cores; não havia sequer tevê em preto e branco"; ${ }^{9}$ e o rádio só seria lançado no país 21 anos depois. De registro imagético documental, restaram apenas poucas fotos.

A conversão dessas imagens referenciadas em imagens de TV revisita o início do século passado com os recursos do presente como forma de recriar para os olhos de hoje, treinados pela técnica, uma cena só captada pelas testemunhas oculares do fato. Trata-se, portanto, como definem Paiva e Sodré $(2004$, p. 90) de uma "experiência de vida mediatizada", de "um novo modo de presença do sujeito no mundo", que Sodré (2006, p. 99) denomina de "telerrealidade" ou "bios virtual".

Nesse "bios virtual", que é

uma espécie de comunidade afetiva de caráter técnico e mercadológico, onde impulsos digitais e imagens se convertem em prática social, essa realidade só é possivel porque a modelização ou as imagens já estão inscritas na própria cultura, na mediação do sujeito consigo mesmo. 0 novo bios é tão-só uma exacerbação do processo, que se torna oficialmente relevante porque intervém nas relações espácio-temporais, estas por meio das quais percebemos 0 mundo e agimos sobre ele (SODRÉ, 2006, p. 99).

Entre a existência real-histórica dos primeiros jogos de futebol no Rio de Janeiro e a nova experiência perceptiva mediatizada pela televisão, dá-se o descompasso que distancia a ideia da representação da ideia de reconstrução, já que a telerrealidade independe de qualquer realidade prévia. Tanto no jornalismo quanto na telenovela, 0 uniforme esportivo foi tomado como um objeto espetacularizado em sua visualidade, um poder comunicativo que ultrapassava seu valor enquanto informação documental. Embora ambas as produções televisivas, cada uma em seu gênero, estivessem apontando para a realidade histórica, funcionando "em nome do princípio da realidade, do sentido de presentificação de algo ausente (re-presentar) e também de autorreivindicação de legitimidade" (SODRÉ, 2006, p. 103), tanto o jornalismo quanto a ficção seriada ofereceram ao público um espetáculo mediatizado, recriado a partir de sua lógica autorreferenciada. E assim o fizeram para serem consumidos pelos olhos "alterados" dos espectadores que já incorporaram as lentes da "tecnologia audiovisual conjugada ao mercado" (SODRÉ, 2006, p. 102).

Assim, não há quebra de legitimidade quando se constata que o blazer listrado em grená, verde e branco usado pelo Oscar Cox de Lado a lado, no jogo com ingleses, resulta de uma impossibilidade histórica. Apesar de, na novela, tal jogo ter sido realizado em 1902, três anos antes de o Fluminense ter trocado o cinza e branco de sua camisa pela marca tricolor, o desencontro não configura erro. Trata-se de legitimidade televisiva. Afinal, de que outro modo poderia o público identificar Cox como jogador do Fluminense senão pelas cores que hoje caracterizam o time? Que diferença faz, aos olhos do público, se a camisa de malha só seria adotada aqui depois de 1910, ano 
da segunda fase da trama? De que outro modo o uniforme dos jogadores da novela poderia confirmar a modelização inscrita no registro coletivo da audiência senão pela presença da camisa de decote em "V" amarrada por um cadarço? Igualmente, para efeito de visualizar a necessidade de proteger a cabeça dos jogadores da corda que amarrava a bola, o que muda na percepção do público se a produção da reportagem do Globo Esporte mandou confeccionar a touca em forma de solidéu ou de boné?

É tudo televisão. Trata-se de uma ambiência virtual em que o real referenciado dá lugar à comunicabilidade do espetáculo autorreferenciado. Na percepção mediatizada pela televisão, a representação da realidade dá lugar à recriação virtual, ao seu duplo eletrônico. Nessa medida, basta criar uma realidade própria que confirme para o espectador a distância espácio-temporal entre o uniforme improvisado do começo do século XX e o do século XXI, desenvolvido tecnologicamente. Para contrapor aos atuais conjuntos high tech que "gerenciam" a ventilação, o conforto e o bem-estar dos atletas, atendendo às suas necessidades fisiológicas, ergonômicas e antropométricas, só mesmo um uniforme de futebol com camisa social, paletó e cinto!

\section{NOTAS}

${ }^{[1]}$ A autora deste artigo e Vitor lorio foram convidados a prestar consultoria aos dois programas sobre 0 início da prática do futebol no Rio de Janeiro.

${ }^{[2]}$ Disponivel em: <www.soumaisflu.com.br/wiki/Uniformes_do_Fluminense>. Acesso em: 12 abr. 2013.

${ }^{[3]} 0$ Fluminense foi o primeiro clube do Rio de Janeiro criado para a prática do futebol.

${ }^{[4]}$ Disponivel em: <http://www.youtube.com/watch?v=bJK6p-GHbnE>. Acesso em: 12 abr. 2013.

${ }^{[5]}$ Disponivel em: <http://tvg.globo.com/novelas/lado-a-lado/videos/t/cenas/v/albertinho-e-fernando-recebemuniformes-e-a-bola-de-futebol/2143794/>. Acesso em: 8 abr. 2013.

[6] Disponivel em: <http://tvg.globo.com/novelas/lado-a-lado/videos/t/cenas/v/fernando-estranha-as-atitudesde-albertinho/2149376/>. Acesso em: 8 abr. 2013.

${ }^{[7]}$ Disponivel em: <http://globotv.globo.com/rede-globo/lado-a-lado/v/fernando-le-as-regras-do-futebol/2143795/>. Acesso em: 10 abr. 2013

${ }^{[8]}$ Disponivel em: <http://tvg.globo.com/novelas/lado-a-lado/videos/t/cenas/v/constancia-assiste-a-partida-defubebol-de-albertinho/2204515/>. Acesso em: 8 abr. 2013.

${ }^{[9]}$ Disponivel em: <http://www.youtube.com/watch?v=bJK6p-GHbnE> $>$. Acesso em: 12 abr. 2013.

\section{REFERÊNCIAS}

CAVALCANTI, Sérgio; MASSON, Nonnato. Futebol carioca começou há 70 anos com bola suiça. Jornal do Brasil, Rio de Janeiro, 30 out. 1971, p. 36.

IORIO, Vitor; IORIO, Patrícia. Paissandu Atlético Clube: pioneiro do esporte no Rio de Janeiro. Rio de Janeiro: PAC, 2001.

PAIVA, Raquel; SODRÉ, Muniz. Cidade dos artistas: cartografia da televisão e da fama no Rio de Janeiro. Rio de Janeiro: Mauad, 2004

SANCHES, Regina Aparecida et alli. Evolução dos tecidos no uniforme de futebol. dObra[s], São Paulo: Estação das Letras e Cores, v. 4, n. 9, p. 21-23, jun. 2010.

SODRÉ, Muniz. As estratégias sensíveis: afeto, mídia e política. Petrópolis: Vozes, 2006. 